\title{
OCCUPATIONAL DISEASES IN THE AUTOMOTIVE INDUSTRY IN CZECHIA - GEOGRAPHIC AND MEDICAL CONTEXT
}

\author{
JAN JAROLÍMEK ${ }^{1,2}$, PAVEL URBAN $^{3,4}$, PETR PAVLÍNEK $^{1,5}$, and DAGMAR DZÚROVÁ ${ }^{1}$ \\ ${ }^{1}$ Charles University, Prague, Czechia \\ Faculty of Science, Department of Social Geography and Regional Development \\ ${ }^{2}$ Public Health Authority of the City of Prague, Prague, Czechia \\ ${ }^{3}$ National Institute of Public Health, Prague, Czechia \\ ${ }^{4}$ Charles University, Prague, Czechia \\ Department of Occupational Medicine, 1st Faculty of Medicine \\ ${ }^{5}$ University of Nebraska at Omaha, Omaha, USA \\ Department of Geography and Geology
}

\begin{abstract}
Objectives: The automotive industry represents the most important industrial sector in Czechia. The objective of this study has been to analyze the occurrence of occupational diseases (OD) in the automotive industry during the period from 2001 till 2014. Material and Methods: Data on OD cases was retrieved from the National Registry of OD. Further, we conducted a survey in automotive companies with focus on occupational health services and positions of the companies in global production networks (GPNs). An analysis of OD distribution in the automotive industry was performed (age, gender, company size and its role in GPNs, regional distribution of studied companies, and regional unemployment rate), and was accompanied by assessment of the quality and range of occupational health services. Results: Employees older than 40 years old have nearly 2.5 times higher probability of OD occurrence as compared with employees younger than 40 years old (odds ratio $(\mathrm{OR})=2.41,95 \%$ confidence interval $(\mathrm{CI}): 2.05-2.85)$. Occupational diseases occurrence probability was 3 times higher for women than for men $(\mathrm{OR}=3.01,95 \% \mathrm{CI}: 2.55-3.55)$. Occupational diseases incidence rates increased with the size of the company (0 OD/10 000 employees in micro enterprises to $57 \mathrm{OD} / 10000$ employees in large enterprises). A particularly steep rise in OD incidents in the automotive industry was observed in the Plzeň Region between 2001 and 2011. An association between OD incidents and the unemployment rate was not statistically confirmed. Conclusions: A statistically significant increase in OD incidents dependent on company size may be arguably attributed to a higher quality of occupational medical services in bigger companies, which ensures better detection and diagnosis of OD. In the Plzen Region, the rapid increase in OD incidents was mainly caused by a change in the production process of automobile textiles in one factory due to the introduction of a glue containing isocyanates, which are potent allergising agents. This led to an increase in occupational allergic diseases - bronchial asthma in particular. Int J Occup Med Environ Health 2017;30(3):455-468
\end{abstract}

Key words:

Occupational diseases, Unemployment, Occupational health services, Automotive industry, Health geography, Czechia

Funding: this study was supported by grants from the Charles University Grant Agency (GAUK) ("Regional Analysis of Occupational Diseases in the Automotive Industry in Czechia and the case study of Medical Geography" No. 803152015) at Charles University in Prague, grant manager: Jan Jarolímek, and by the Ministry of Health, Czechia "Conceptual development of research organization" No. RVO-SZÚ/2016 at the National Institute of Public Health, grant manager: Jitka Sosnovcová. Received: February 8, 2016. Accepted: April 26, 2016.

Corresponding author: J. Jarolímek, Charles University, Faculty of Science, Department of Social Geography and Regional Development, Albertov 6, 128 00 Prague, Czechia (e-mail: jarolija@natur.cuni.cz). 


\section{INTRODUCTION}

Differences in the geographical occurrence of diseases and among social classes have stood at the centre of the scientific interest for a long time. The differences in health arise among others as a consequence of different social and economic circumstances [1-5] which include occupational factors. The most serious consequences of an exposure to the occupational risk factors from medical and socio-economic points of view are occupational diseases (OD). The occurrence of OD is characterized by distinct regional and sector differentiation and shows considerable time and space dependent dynamics [6].

Studies dealing with occupational diseases have been widely used in the geographical analysis since the beginning of the 1980s [7-9]. The more frequent use of geographical information systems (GIS) in the research on variability of factors affecting the health of employees has been evident recently [9-11]. Several studies have used a combination of spatial and non-spatial information from several data sources available at macro- or at micro-level [12-14].

Delaunay et al. [11] have underscored the importance of research on monitoring of employees' health and safety, while they also warn that the obtained data is often rather complicated, diverse, unstructured, and it is necessary to approach the data at different levels of analysis and to work with them separately. Each group of specialists (physicians, occupational health and safety specialists, and geographers) usually processes and evaluates data separately and this is done not only at national or regional levels, but even at local levels (individual companies) i.e., micro-level. The companies' data is especially hard to obtain [9] and even if the data is accessible, it is difficult to process and face the limitations - e.g., the small number problem $[15,16]$.

In Czechia, the occurrence of OD has generally shown a stable decreasing trend over last twenty years in terms of both absolute numbers of reported cases and their relative incidence. The most noticeable exception has been the automotive industry, wherein the OD occurrence has shown a significant and continuous increase [6,17].

The authors use term 'the automotive industry' according to the Classification of the Statistical Classification of Economic Activities in the European Community (Nomenclature statistique des Activités économiques dans la Communauté Européenne - NACE), division C29 Manufacture of motor vehicles (except motorcycles), trailers and semi-trailers. The automotive industry forms a crucial branch of the Czech economy. It contributes approximately $25 \%$ to the total industrial production output, $23.4 \%$ - to the total export, and $7.4 \%$ - to the gross domestic product [18]. The 2014 production reached 119 automobiles per 1000 inhabitants [19], which represented the second highest count of manufactured automobiles per capita in the world (following Slovakia with 183 automobiles per 1000 inhabitants). By comparison, the average number of cars manufactured in 28 countries in the European Union (EU28) was 35 per 1000 inhabitants. The study of Pavlínek and Ženka [20] showed that $1 / 4$ of Czech micro-regions were overspecialized in the automotive industry. While in 2001 OD in this sector occurred only in $1.7 \%$ of all reported OD cases, the percentage share increased to $11.4 \%$ in 2014 [21]. This growth in the OD occurrence was the main reason for our decision to investigate the OD occurrence in the automotive industry.

With respect to the employment, the industry still constitutes a dominant economic sector in Czechia. Its 2012 percentage share of the total employment was $36 \%$ contrary to $22.7 \%$ in the EU. The crucial part of industry in terms of both gross value added and the number of employees is the manufacturing industry (NACE section C), and especially the automotive industry (division C29). The employees in this division comprised $4 \%$ of economically active population (EAP) in Czechia in 2014 in contrast to 
the average 1.4\% of EAP in EU28 countries (The Czech Statistical Office (CSO), 2014 [22]).

Such a high volume is not surprisingly accompanied with some adverse health consequences, specifically with occurrence of occupational diseases. These represent health and socioeconomic problems not only for employees, but they create complications for employers as well. OD occurrence potentially interferes with the continuity of production and forces employers to search for and to train new employees, thereby causing significant time and economic losses.

In this study, we addressed the increased incidence of OD in the automotive industry in Czechia, focussing on the following questions:

- Is there a relationship between the OD incidence rate in the automotive industry and a company size, and a company's role in the global production networks?

- Is there a relationship between the OD incidence rate in the automotive industry and socio-demographic indicators (gender and age) of employees?

- Is there a relationship between regional variability of the OD incidence rate in the automotive industry in Czechia and the unemployment rate?

\section{MATERIAL AND METHODS}

\section{Data}

The period from 2001 till 2014 was chosen for our research. The first source of data was the National Registry of Occupational Diseases [23] (hereafter referred to as the Registry), where all cases of occupational diseases acknowledged in Czechia were registered. In the Czech social system, only the diseases enumerated in the List of Occupational Diseases may be considered to be occupational diseases in the medicolegal term, including the entitlement to compensation. From the Registry, aggregated and anonymized cases of OD linked with CZ-NACE in the division $\mathrm{C} 29$ were selected. They were further divided according to the registration numbers of companies, where the OD cases originated from.
The second source of data was a survey we had conducted using questionnaires that we had designed. The survey was aimed to obtain relevant information about particular situations in each company the OD cases were reported from. The questionnaires were sent to 350 companies which belonged to the division C29 according to the Registry of Job Categorization. The questionnaire consisted of 11 questions. The first part of the questionnaire dealt with a company's identification data and its position in global production networks (GPN) [24,25]. The second part of the questionnaire focused on the OD and occupational health services (OHS). The aim of the questionnaire was to determine the workforce composition by age and gender, the average wage, the range of provided $\mathrm{OHS}$, and the OD prevention system.

Companies were classified into 4 categories: i) micro enterprises which employ fewer than 10 employees, ii) small enterprises with 10-50 employees, iii) medium-sized enterprises with 50-250 employees, and iv) large enterprises with more than 250 employees. The questionnaire was designed with regard to the law No. 373/2011 Coll on specific health services [26], which set employers' obligation to ensure OHS and defined the scope of the services in compliance with the International Labour Organization (ILO) Convention No. 161/1985 [27]. We were further interested whether the provider of the OHS also performed workplace surveillance and/or other additional activities. A total of 247 (71\%) companies out of 350 responded and returned completed questionnaires. Their answers were summarized in the Table 1. This data then also served the purpose of estimation of the OD incidence.

Besides the absolute numbers of OD cases, we also used a relative indicator - the OD incidence rate, calculated as a number of newly reported OD cases in a particular industrial sector per 10000 economically active persons (EAP) in the same industrial sector per year. 
Table 1. Characteristics of 247 companies from the automotive industry in Czechia, 2001-2014

\begin{tabular}{|c|c|c|c|c|c|c|c|}
\hline \multirow{3}{*}{ Company* } & \multicolumn{5}{|c|}{ Employees } & \multirow{3}{*}{$\begin{array}{l}\text { Occupational } \\
\text { diseases } \\
{[\mathrm{n}]}\end{array}$} & \multirow{3}{*}{$\begin{array}{c}\text { Monthly } \\
\text { income } \\
\text { [CZK] } \\
\text { (M) }\end{array}$} \\
\hline & \multirow[t]{2}{*}{$\begin{array}{l}\text { total } \\
{[\mathrm{n}]}\end{array}$} & \multirow[t]{2}{*}{$\begin{array}{c}\text { women } \\
{[\mathrm{n}]}\end{array}$} & \multirow[t]{2}{*}{$\begin{array}{c}\text { men } \\
{[\mathrm{n}]}\end{array}$} & \multicolumn{2}{|c|}{$\begin{array}{c}\text { age } \\
\text { [years] } \\
(\mathrm{M})\end{array}$} & & \\
\hline & & & & women & men & & \\
\hline Micro $(\mathrm{N}=8)$ & 40 & 9 & 31 & 38.7 & 45.8 & 0 & 18543 \\
\hline Small $(\mathrm{N}=54)$ & 1446 & 412 & 1034 & 42.8 & 42.2 & 2 & 21955 \\
\hline Medium $(\mathrm{N}=77)$ & 9944 & 4054 & 5890 & 40.1 & 39.7 & 42 & 25792 \\
\hline Large $(\mathrm{N}=108)$ & 98369 & 34580 & 63789 & 39.2 & 37.9 & 563 & 28452 \\
\hline $\operatorname{Total}(\mathrm{N}=247)$ & 109799 & 39055 & 70744 & 40.2 & 41.4 & 607 & 23686 \\
\hline
\end{tabular}

* The size of the companies was classified according to EU 2003/361/ES [39].

$\mathrm{M}$ - mean.

1 euro $\approx 27 \mathrm{CZK}$.

Since the information on the number of EAP employed in the automotive industry was available only for census years, i.e., 2001 and 2011, the OD incidence rates could only be calculated for these years. The Czech Statistical Office provided the information on the average wages in the automotive industry in years 2001 and 2011. Regional data was obtained from the regional statistical yearbook of the CSO [22].

The unemployment rate in Czechia is chosen as one of the explanatory variables. The CSO defines the general unemployment rate as the percentage share of the unemployed in the total workforce, where a numerator and a denominator are calculated according to international definitions and recommendations applied to the Workforce Sample Survey.

The location quotient is used for quantifying the concentration of the automotive industry in a particular region. The location quotient (lq) expresses a concentration of a given activity in a particular region in relation to the superordinate region - i.e., Czechia. Its numerator is defined as a ratio of the workforce employed in a given industrial section $\mathrm{i}$ (in this case the automotive industry) in a region $\mathrm{j}$ to the total workforce in a region $\mathrm{j}$; its denominator is defined as a ratio of the workforce employed in an industrial section $\mathrm{i}$ in the superordinate region to the total workforce:

$$
l q=\left(\frac{E_{J i}}{E_{j}}\right) /\left(\frac{E_{i}}{E}\right)
$$

where:

lq - location quotient,

$\mathrm{E}_{\mathrm{Ji}}$ - regional industrial employment (in this case the automotive industry),

$\mathrm{E}_{\mathrm{j}}$ - regional total employment,

$\mathrm{E}_{\mathrm{i}}$ - national industrial employment,

E - national total employment.

Afterwards, we determine the Lorenze curve (which is one of the most common methods of graphical representation of diversification) and the Gini coefficient (which is a measure of inequality of spatial distribution of a studied phenomenon). In that case, the Gini coefficient may be approximated by using various techniques for interpolating the missing values of the Lorenz curve, if $\mathrm{X}_{\mathrm{k}}, \mathrm{Y}_{\mathrm{k}}$ are the known points on the Lorenz curve, with the $X_{k}$ indexed in increasing order $\left(\mathrm{X}_{\mathrm{k}-1}<\mathrm{X}_{\mathrm{k}}\right)$.

If the Lorenz curve is approximated on each interval as a line between consecutive points, then the area B may be 
approximated with trapezoids and the equation 2 is the resulting approximation for $\mathrm{G}$ :

$$
\mathrm{G}=1-\sum_{\mathrm{i}=0}^{\mathrm{n}}\left(\mathrm{X}_{\mathrm{k}}-\mathrm{X}_{\mathrm{k}-1}\right)\left(\mathrm{Y}_{\mathrm{k}}-\mathrm{Y}_{\mathrm{k}+1}\right)
$$

where:

G - Gini coefficient,

$\mathrm{X}_{\mathrm{k}}$ - the cumulated proportion of the population variable, for $\mathrm{k}=0, \ldots, \mathrm{n}$, with $\mathrm{X}_{0}=0, \mathrm{X}_{\mathrm{n}}=1$,

$\mathrm{Y}_{\mathrm{k}}$ - the cumulated proportion of the employment variable, for $\mathrm{k}=0, \ldots, \mathrm{n}$, with $\mathrm{Y}_{0}=0, \mathrm{Y}_{\mathrm{n}}=1$,

$\mathrm{Y}_{\mathrm{k}}$ - should be indexed in non-decreasing $\operatorname{order}\left(\mathrm{Y}_{\mathrm{k}}>\mathrm{Y}_{\mathrm{k}-1}\right)$.

The relationships between the OD occurrence and a gender or age of employees were tested using $\mathrm{Chi}^{2}$ test in a $2 \times 2$ contingency table. The results were expressed as the odds ratio (OR) with a $95 \%$ confidence interval (CI). The correlation between the unemployment rate and the OD occurrence was tested by the linear regression and calculation of the Pearson correlation coefficient. The statistical analysis was performed at Interactive Statistical Pages [28] followed by verification using an Excel (CHITEST function). The level of statistical significance was set at $\mathrm{p}<0.05$.

Several of the results were depicted graphically in map projections created in the geographical information systems (GIS) using geographic database $\operatorname{Arc}^{\circ} \mathrm{C}^{\odot}$ and software e ArcMap v. 10.3.

\section{RESULTS}

Altogether 1054 OD cases were reported in the automotive industry (section C29) during the studied period from 2001 till 2014. The most frequent of them included the carpal tunnel syndrome, allergic contact dermatitis due to chemical products, and allergic asthma. The analysis of data from the Registry revealed an increasing proportion of the OD cases in the automotive industry to all recognised OD cases. While the 2001 percentage share of

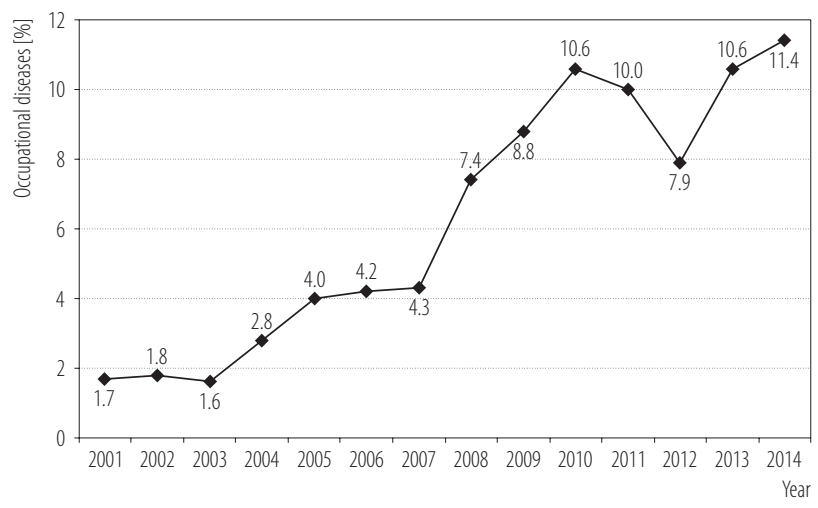

NACE (Nomenclature statistique des Activités économiques dans la Communauté Européenne) - Statistical Classification of Economic Activities in the European Community.

Fig. 1. Proportion of occupational diseases (OD) in the NACE industrial section $\mathrm{C} 29$ (manufacture of motor vehicles) to all OD cases in Czechia, 2001-2014

the OD cases in the automotive industry was only $1.7 \%$, it rose to $11.4 \%$ by 2014 (Figure 1).

\section{Location quotient of the automotive industry for the districts in Czechia}

The Figures 2 and 3 depict the location quotients of the automotive industry in Czechia in 2001 and 2011, respectively. The total of 24 districts exceed the lq value 1.0 (meaning the above-average concentration of a given industry in the region) in 2001.

However in 2011, the number of districts, which exceeded the lq value 1.0 rise to 34 . On the other hand, the highest observed values of the lq dropped significantly at the same time.

A calculation of Gini coefficients has served as a further confirmation of the observed development of the automotive industry distribution between 2001 and 2011. Their values have supported the finding that the automotive industry in Czechia had been highly centralized and covered a considerably smaller area in 2001. Whereas, the trend for a more even distribution became apparent in 2011 and almost every district got gradually involved. 


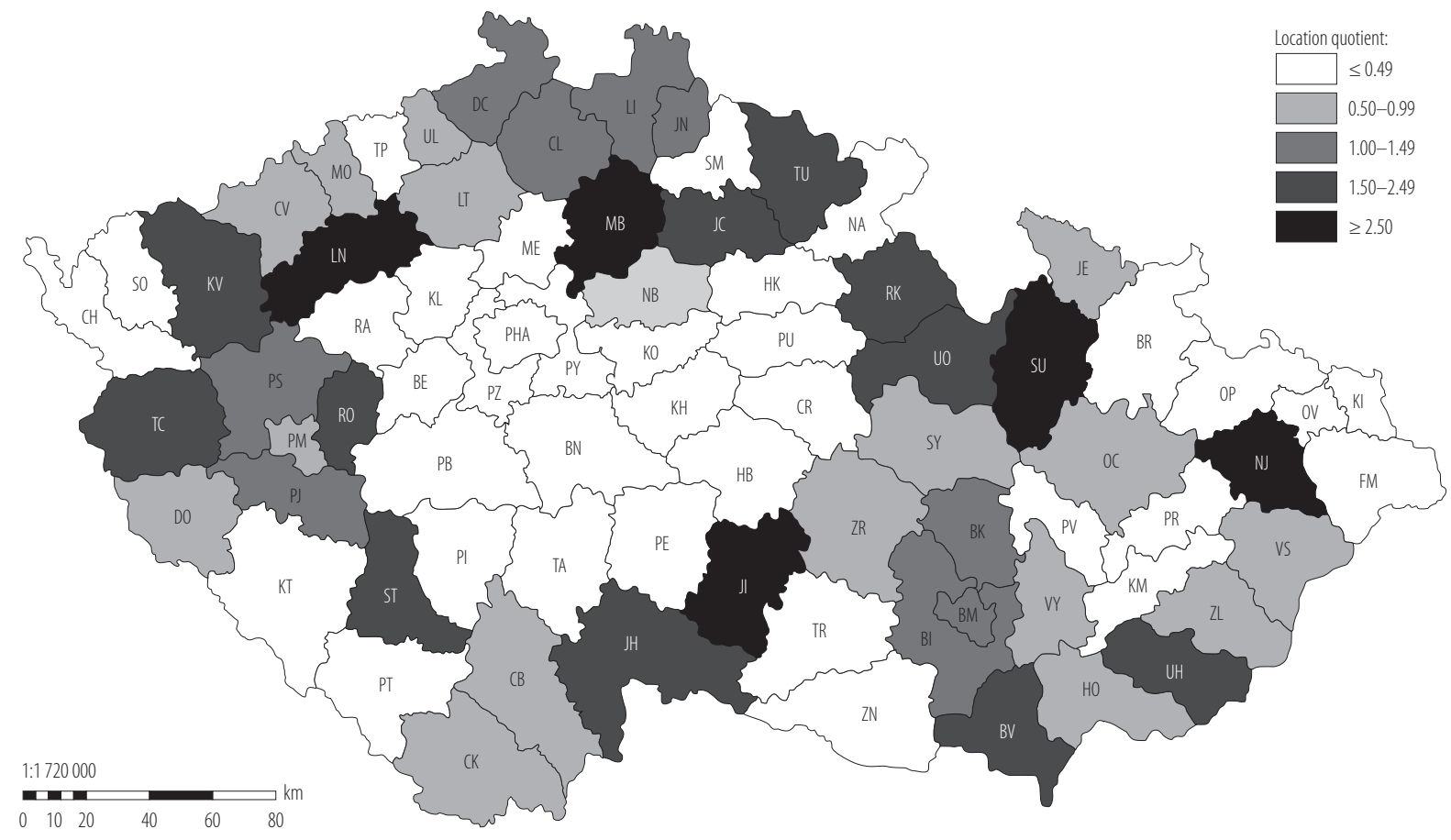

Data from our survey, 2014.

Fig. 2. Concentration of automotive industry in Czechia, 2001

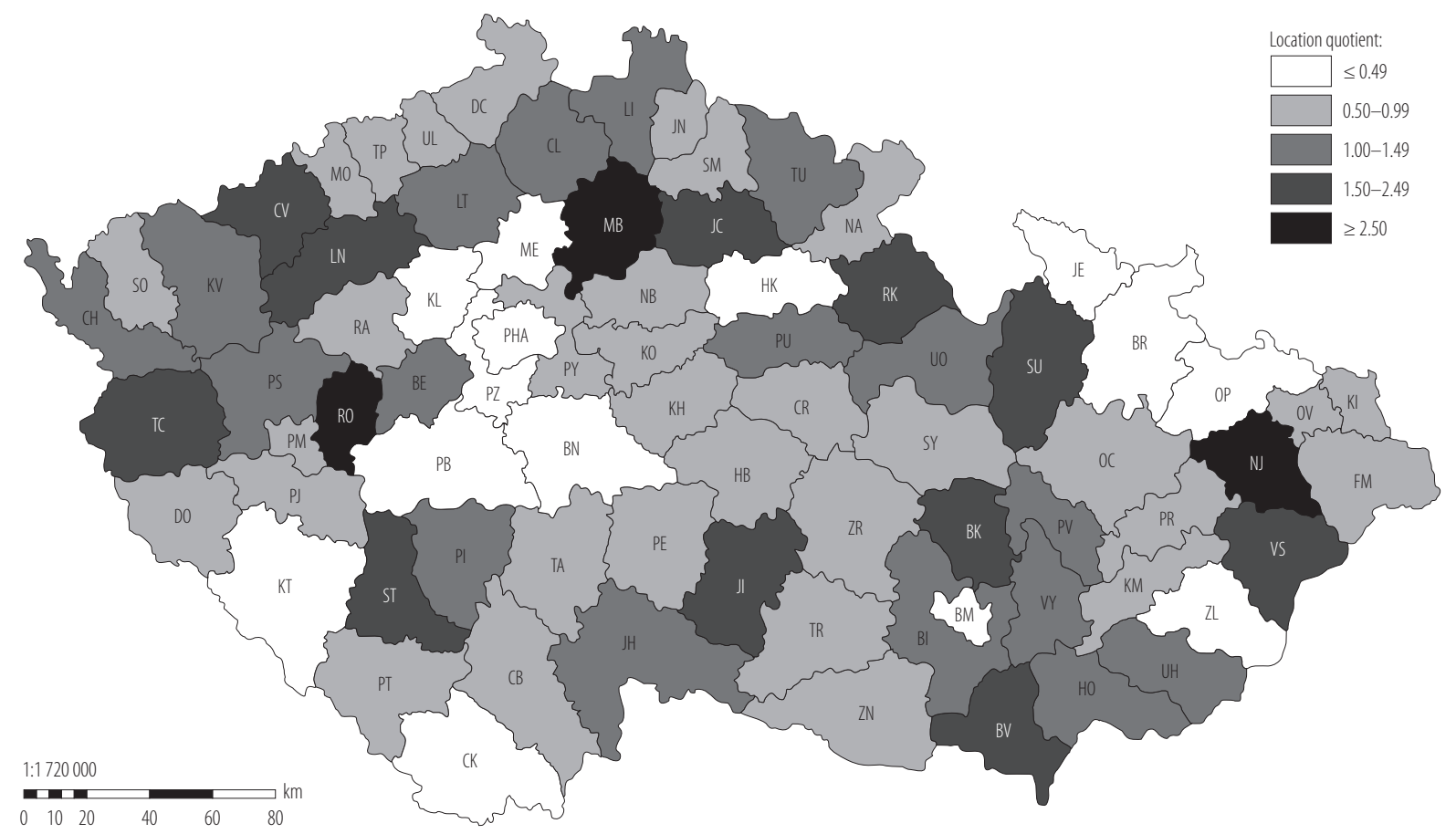

Data from our survey, 2014.

Fig. 3. Concentration of automotive industry in Czechia, 2011 


\section{Occupational diseases incidence rate} in districts of Czechia

The Figures 4 and 5 were created for a better visualisation of the regional distribution of the OD incidence rate in Czech districts.

In 2001, 7 districts exceeded the OD incidence rate 12.01 per 10000 EAP employed in C29. In 2011, 12 districts exceeded this OD incidence rate. On a regional level, striking change was observed in the Plzeň Region, where the OD incidence rate soared from 4.4 OD cases/10 000 EAP in C29 in 2001 to 42.8 OD cases/ 10000 EAP in C29 in 2011.

\section{Sociodemographic indicators and OD}

Altogether 350 companies involved in the industrial section C29 with the total of more than 140 thousand employees were approached to participate in our survey, and 247 of them responded with a completed questionnaire. The response rate was $70.6 \%$. Thus our set of data consisted of 109799 employees from those 247 companies, which represented $78 \%$ of all EAP employed in C29 in 2011 (according to the Population and Housing Census in 2011, CSO [22]). This may be considered to be a well representative sample. The structure of the data set according to the company size was as follows: $43.7 \%$ of large enterprises, $31.2 \%$ of medium-sized enterprises, $21.9 \%$ of small enterprises, and $3.2 \%$ of micro enterprises. The employees of the large enterprises had the highest average gross monthly wage: 28454 CZK (ca. 1070 euro). The wage tended to decrease with the decreasing size of the enterprise. The average gross monthly wage over $20000 \mathrm{CZK}$ was also reached by middle-sized enterprises (25 $792 \mathrm{CZK}$ ), and small enterprises (21 $955 \mathrm{CZK}$ ); only micro enterprises did not surpass it (18 $543 \mathrm{CZK})$.

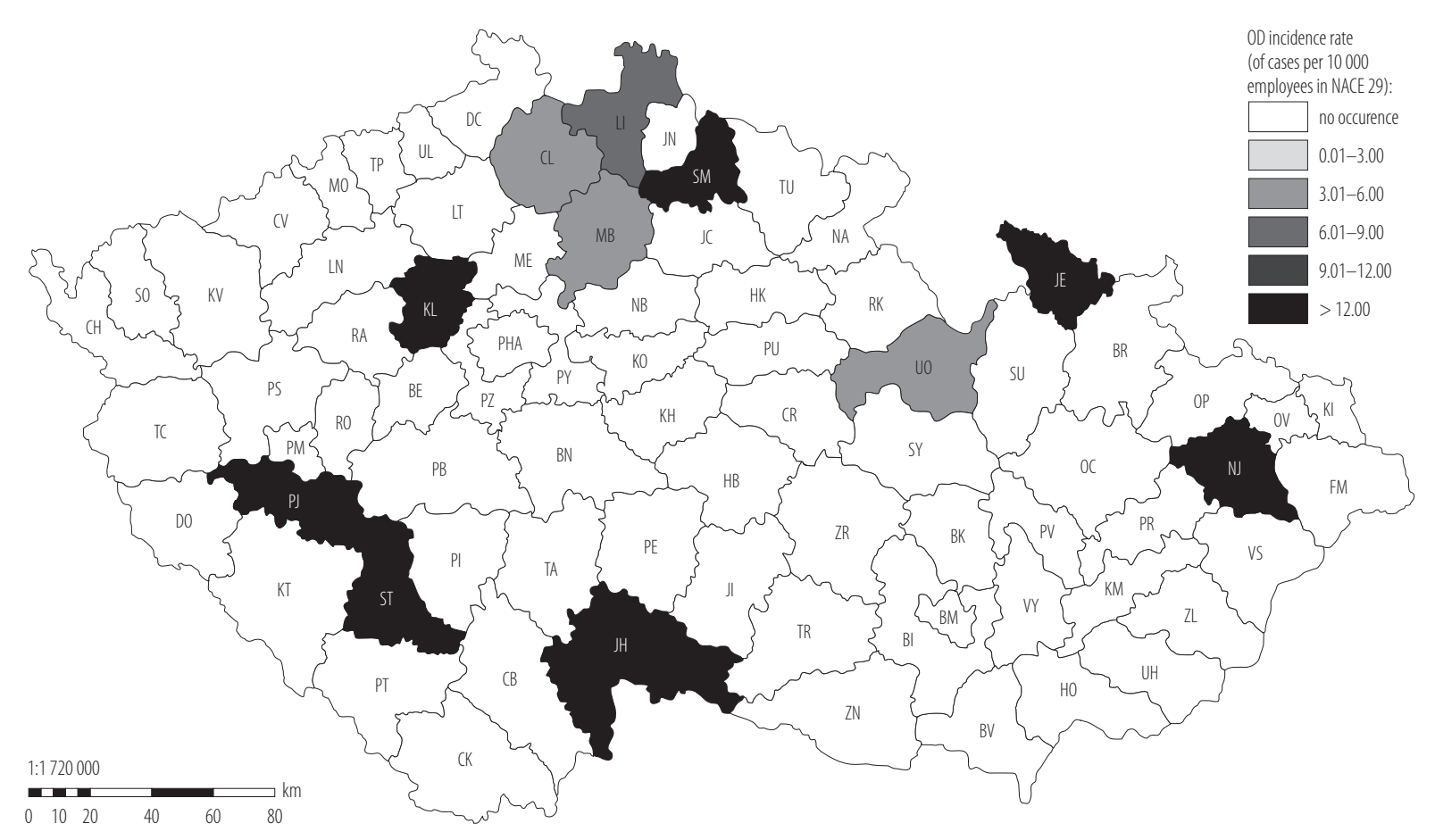

NACE (Nomenclature statistique des Activités économiques dans la Communauté Européenne) - Statistical Classification of Economic Activities in the European Community.

Data from the National Register of Occupational Diseases, 2014 [23].

Fig. 4. Occupational diseases (OD) incidence rate in the automotive industry in Czechia, 2001 


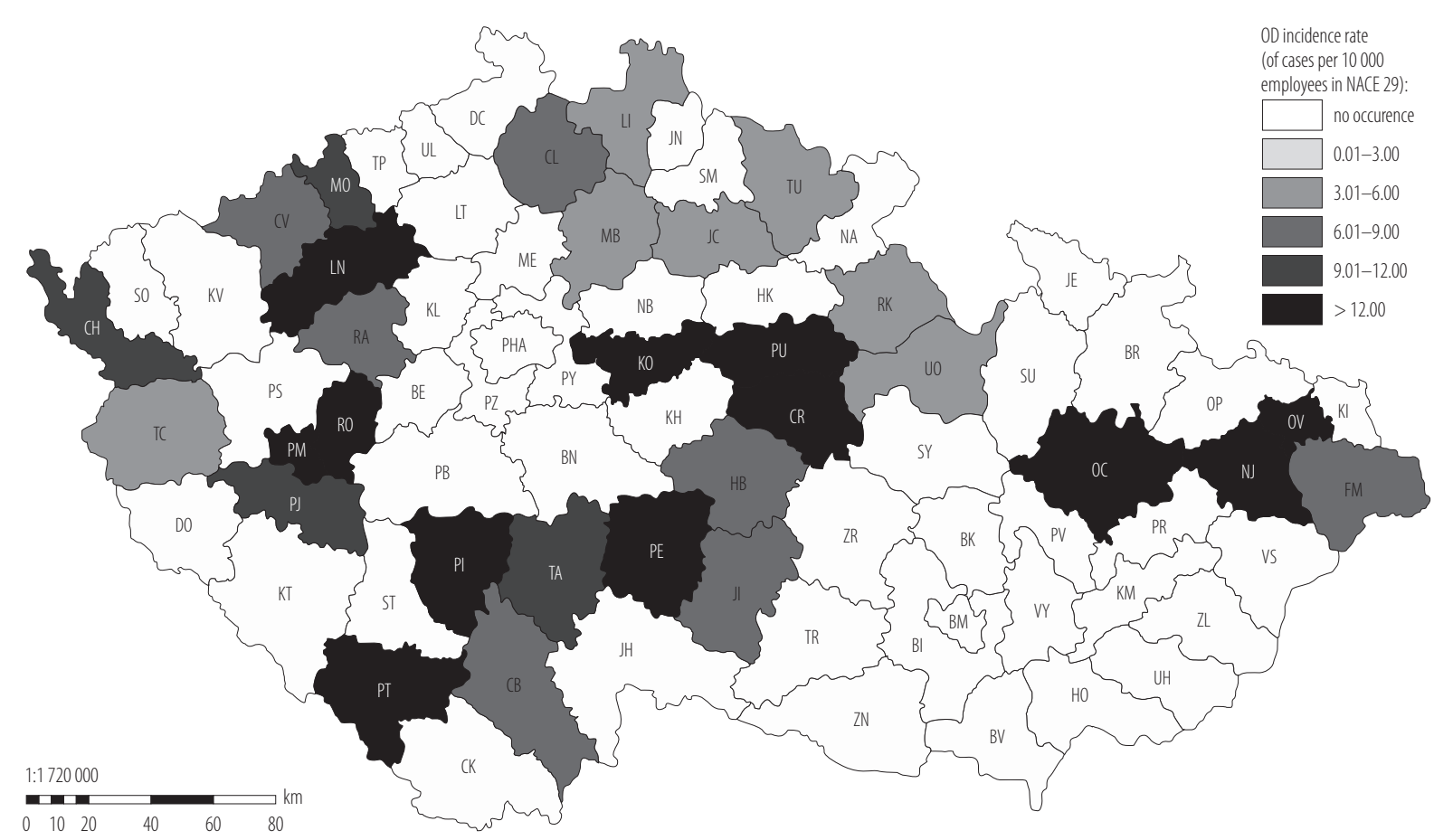

NACE - as in Figure 4.

Data from the National Register of Occupational Diseases, 2014 [23].

Fig. 5. Occupational diseases (OD) incidence rate in the automotive industry in Czechia, 2011

Out of 1054 OD cases recognized in the industrial section C29 during the period from 2001 till 2014, altogether 607 cases were reported in 247 companies participating in our survey.

\section{Age and gender of the employees and OD}

The set of data was divided into 2 groups - the employees older and younger than 40 years old or men and women (Table 2).

The ratio of employees younger than 40 years old (included) to those older than 40 years old in C29 companies was $58 \%$ to $42 \%$. However, the proportion of employees under and over the age of 40 years old with the reported OD case was $37 \%$ to $63 \%$ respectively, which corresponded to $\mathrm{OR}=2.41$ (95\% CI: 2.05-2.85), i.e., the older group of employees was 2.4 times more at risk of the OD.

The employees from the C29 companies, which participated in our survey, consisted of $64 \%$ men
Table 2. Age and gender of the employees with occupational diseases $(\mathrm{OD})$ in the automotive industry in Czechia, 2001-2014

\begin{tabular}{lcc}
\hline \multicolumn{1}{c}{ Characteristics } & $\begin{array}{c}\text { OD cases } \\
\text { in 2001-2014* } \\
{[\mathrm{n}]}\end{array}$ & $\begin{array}{c}\text { Employees } \\
\text { in 2014* } \\
{[\mathrm{n}]}\end{array}$ \\
\hline Age & & \\
$\quad$ 4 40 years & 223 & 64076 \\
$\quad>40$ years & 384 & 45723 \\
$\quad$ total & 607 & 109799 \\
Gender & & \\
men & 228 & 70744 \\
women & 379 & 39055 \\
total & 607 & 109799 \\
\hline
\end{tabular}

* In 247 companies involved in the survey.

and $36 \%$ women. However the ratio of men to women, which were diagnosed with the OD during 20012014 was $38 \%$ to $62 \%$ which corresponded to OR $=3.01$ 


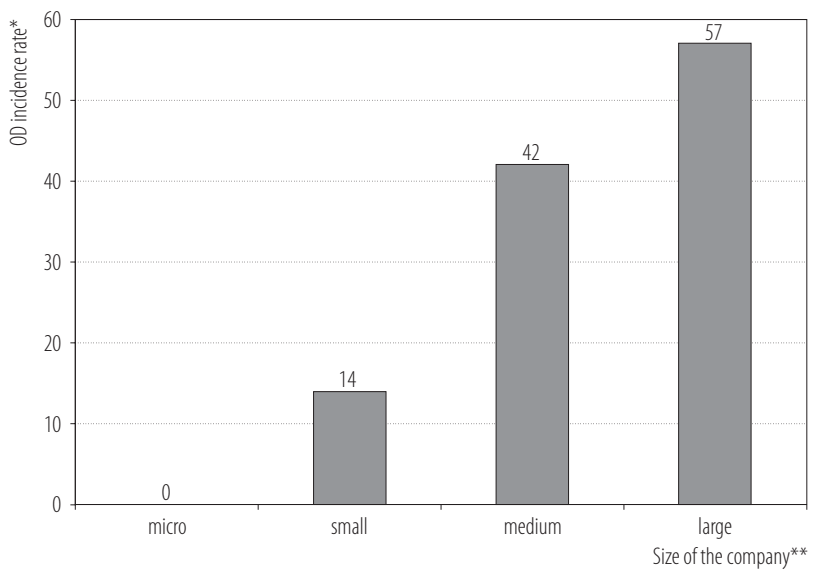

* Of cases per 10000 employees in CZ-NACE C29.

** According to EU 2003/361/ES [39].

Fig. 6. Occupational diseases (OD) incidence rate in the automotive industry in Czechia according to the company size, 2014

(95\% CI: 2.55-3.55), i.e., women were 3 times more at risk of the OD than men.

The Figure 6 depicts the OD incidence in the studied companies depending on the company size. The increase in the OD incidence rate with the size of the company is obvious.

The Figure 7 depicts companies divided according to their position in the GPN. A monotonous relation to the OD

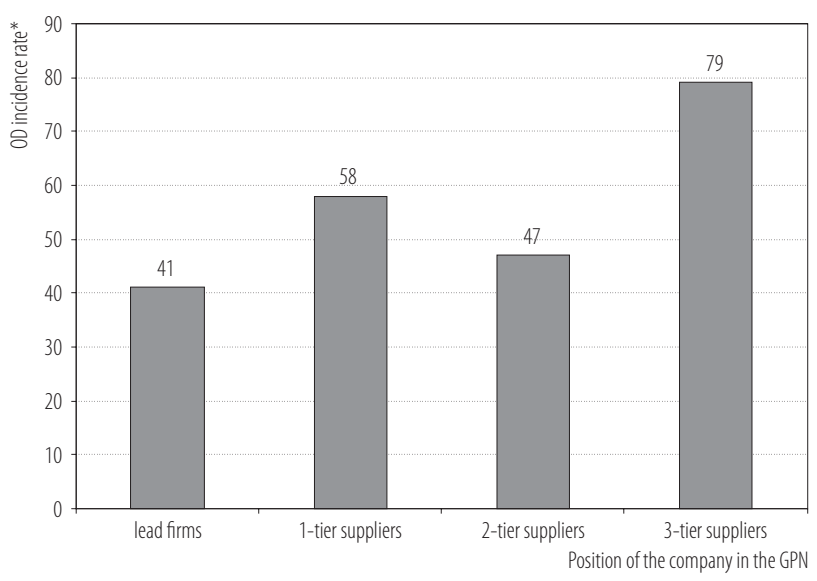

* Of cases per 10000 employees in CZ-NACE C29.

Fig. 7. Occupational diseases (OD) incidence rate in the automotive industry in Czechia according to the position of a company in the global production networks (GPN), 2014

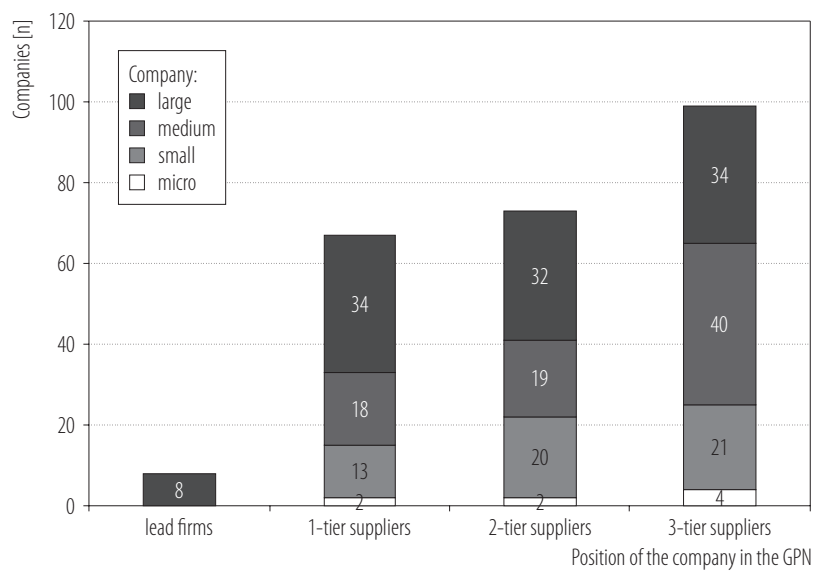

Fig. 8. Company size and its position in the global production networks (GPN) in the automotive industry in Czechia, 2014

incidence rate is not apparent. The highest OD incidence rate was observed for third tier suppliers. Large and medium-sized enterprises dominated among third tier suppliers (Figure 8).

\section{Quality and scope}

\section{of the occupational health services (OHS)}

The analysis of the questionnaires revealed that $97.2 \%$ of the companies provided the OHS in compliance with the law No. 373/2011 Coll. [26] on specific health services; majority of the companies $(89.5 \%)$ relied on external services, while $7.7 \%$ of companies used internal professional employees. Only $2.8 \%$ of companies did not provide the OHS at all.

As for the companies providing the OHS, we investigated whether the OHS were limited to medical examinations or if they also encompassed any form of workplace surveillance. A workplace risk assessment was performed in 192 (80\%) out of 240 companies. Additionally, consulting services were employed by 182 companies (almost 76\%). About a half of the companies actively participated in the analysis of occupational injuries and diseases. Finally, the smallest attention was directed to occupational rehabilitation, which was provided by fewer than $20 \%$ of the companies. An active system of the OD prevention was implemented by 233 companies $(94.3 \%)$. Besides a compulsory pre-employment 
medical examination, the most common form was training the employees how to prevent negative health effects such as muscle overstraining. Additionally, some of the companies (mostly the bigger enterprises) offer the employees benefit system with contributions to recreation and/or freetime activities, and they also perform a continuous evaluation of operation and its automation, and technological and technical improvements of operations especially modernization (e.g., improvements of ergonomics).

\section{Relation between the OD incidence rate in C29 and the unemployment rate in Czechia}

No significant association between the OD incidence rate and the unemployment rate was found (2001: Pearson's $r=0.181, p=0.554 ; 2011: r=-0.154, p=0.599$ ). A comparison of situations in both census years 2001 and 2011 revealed a decrease in the unemployment in most of the districts and increase in the OD rates, although a certain group of districts behaved differently.

\section{DISCUSSION}

The aim of our study has been to map the occurrence of OD in the automotive industry in Czechia from the geographical point of view and to correlate it with socio-economic determinants of health. The study was based on data from the Registry of Occupational Diseases [23] and on data from our own representative survey of 247 companies involved in $\mathrm{C} 29$.

We attempted to analyze the steep increase in the occurrence of OD in the automotive industry (C29) during the period from 2001 till 2014, which was in stark contrast to general decrease in the OD occurrence observed in other branches of economic activities in Czechia.

Several factors may underlie this increase. First of all, the proportion of employment in C29 to the total employment was increasing and ranked Czechia first among the EU27 countries. The number of employees in the automotive industry in Czechia rose from 58 thousand in 1994 to 146 thousand in 2011 (CZ-NACE 29), which represented $11.4 \%$ of total employment in the industry in 2011 [29] and 3\% of the total employment in Czechia, while it was only $2 \%$ in Germany, and $0.6 \%$ in France [30]. The previous decade was characterized by the transfer of automobile production. The employment in the automotive industry has been decreasing in Western Europe, while it has been continually growing in the states of Central and Eastern part of Europe [31]. The increase in the OD occurrence in this section of industry may be at least partially explained by high effectiveness of production in C29, with high pace of work, which often consists of repetitive motions.

Examining the data according to age has revealed that employees over the age of 40 years old have been 2.4 times more at risk of developing OD than the younger employees. This nationwide finding is in agreement with our previous results limited to the Central Bohemian Region [17]. The relationship between the OD incidence and age is typically characterized by bimodal distribution. The first peak corresponds to young people shortly after they start to work. The explication is their lack of experience, skills, and not yet perfect working habits, which increase the risk of OD and/or injury. The second peak of the OD occurrence is evident around the 5th and 6th decades of life and is related to a gradual deterioration of physical and mental abilities, and exhaustion of compensation mechanisms of an organism typical for more advanced age [32].

We have further addressed the OD occurrence from the gender point of view. Women were shown to be 3 times more likely diagnosed with the OD than men. The difference was statistically significant and this result concurred with our previous study [17]. A likely explanation may be due to differences in physical constitutions, as men are generally better at coping with increased physical stress than women who are thus more susceptible to overstraining the capacity of their musculoskeletal system. 
The size of enterprises and their position in GPNs have been other factors that we have focused on. The OD incidence has been positively correlated with the size of the company. The simplistic interpretation would conclude that health risks are greater in larger enterprises than in smaller ones, however, this is in contradiction with practical experience. In fact, larger enterprises usually provide employees with better occupational health services, which means that the employees are more likely to be correctly and timely diagnosed with health problems connected with their occupation than employees in smaller enterprises. This notion is further supported by the results of our survey, which shows that $38 \%$ of micro enterprises do not provide any OHS, and $55 \%$ of enterprises from the same category provide only insufficient OHS. The situation improves in the category of small enterprises, where only $4 \%$ provide no OHS, and $34 \%$ provide insufficient OHS.

Contrary to the size of enterprise, the correlation between OD incidence and the position of the company in the GPNs did not render any clear trend. Only the results for the third tier suppliers were distinctly different from the others showing the highest OD incidence rate of them all (6.4 OD/10 000 employees). One possible explanation may be implied from the Figure 8, where it is apparent that among the third tier suppliers there are mostly the medium-size and large companies. As discussed above, the OD incidence rate is increasing with the size of company, and therefore it is logical to expect a higher OD incidence.

Ženka and Pavlínek [33] also point out that the third tier suppliers are at the most disadvantageous position in the whole supply chain as they are dictated by all others - automobile factories, and first and second tier suppliers - what, where, and for how long they should supply. For apparent reasons, third tier suppliers are under a constant pressure to reduce manufacturing costs and prices, for which they sell their goods. These demands for higher effectiveness and lower costs may be explained by overall increase in the pace of work, which in turn may lead to the increase in OD incidence due to overstraining of workers especially in the case of suppliers with a high percentage share of a manual labour.

The unemployment rate is another socio-economic factor, which could affect the OD occurrence in C29. We studied data from 14 Czech regions obtained in census years 2001 and 2011, however, no statistically significant correlation was found between the unemployment rate and OD incidence. Nevertheless, as mentioned above, we have observed a remarkable situation in the Plzeň Region which deserves a separate discussion. Even though the rate of unemployment in this particular region between the census years 2001 and 2011 was virtually unchanged, the OD incidence rate soared from 4.4 OD cases/10 000 EAP in C29 in 2001 to 42.8 OD cases/10 000 EAP in C29 in 2011. This was so different from what we saw elsewhere that we searched for an explanation. It appeared that the source of the enormous increase in the OD incidence lay in one company manufacturing accessories for motor vehicles. While the company had only one reported OD case in 2001, the number rose to 33 in 2011.

Closer examination revealed that the growth of OD cases started in 2008. According to the information provided by an OHS provider, the increase was caused by the change in the production process. Since 2007, the company had started to use a glue SikaMelt $9630 \mathrm{M}$ in the production of automobile textiles. The glue contained isocyanates, especially diphenylmethane-4,4-diisocyanate. Even though the glue was applied by robots, the isocyanates got released into the air during a curing process. Despite the fact that permissible exposure limit (PEL) in the air was not exceeded, isocyanates were such a strong allergen, that the amount was sufficient to induce allergic diseases - particularly bronchial asthma - in sensitive individuals. The case is an illustrative example, how an analysis at the hierarchic higher level may conceal important relations which exist at hierarchic lower levels (Simpson's paradox). 
The top three occupational diseases in the case of the automotive workers in our study included the carpal tunnel syndrome, allergic contact dermatitis, and bronchial asthma. This is in basic agreement with the scarce studies on this issue we have been able to identify in the literature. Yakut et al. [34] detected contact dermatitis in 5.9\% of 405 automotive workers. Automotive manufacturing ranked high among other industrial sectors in the incidence of contact dermatitis also in the study by McDonald et al. [35]. High risk of exposure to diisocyanate in the automotive industry, we have observed, was described also in the study by Randolph et al. [36], especially concerning allergic respiratory and skin diseases. Having studied 200 insurance claims of automotive workers, Nelson et al. [37] found that there was a high risk of cumulative trauma disorders, namely of the carpal tunnel syndrome, especially in the assembly automotive plants.

The carpal tunnel syndrome, contact dermatitis and some allergic respiratory diseases, such as allergic rhinitis and conjunctivitis, are fortunately no life threatening conditions. If they are present in a mild form, the workers may hide the problems and not report them to the physicians during periodic medical examinations. They do it frequently because they are afraid of losing their jobs. This contributes to the underreporting of occupational diseases, especially in micro and small enterprises.

\section{Limitations of the study}

Despite our effort, our study has several limitations. One of them is the small number of cases, which lowers the power of statistical tests and increases a probability of type II error. We have assessed the OD for the whole studied period in order to minimize the random error. However, this approach has shortcomings too, as the numerator and denominator in the calculation of the OD incidence have not always been from the absolutely identical period. Therefore the obtained results are associated with some uncertainty.
Another limiting factor of our research is an inability to perform an international comparison. Currently, there is no uniform methodology which would standardize recognition of OD and their statistical recording. The harmonization of national OD systems was tested as a part of the European Occupational Diseases Statistics (EODS) project organized by Eurostat. It appeared that several countries were unable to fulfil EODS requirements due to technical or legal reasons, and hence the European Commission decided to suspend the project [6]. One possible solution to this problem was suggested in the work by Stocks et al. [38].

\section{CONCLUSIONS}

Occupational diseases are in principle preventable. The reason for the observed increase in the OD occurrence in C29 in Czechia may be at least partially explained by a high effectiveness of production in this industrial section, with high intensity of work, which often consists of repetitive motions. More comprehensive provision of proper occupational health services might be one of the measures how to improve the current situation.

\section{ACKNOWLEDGMENTS}

The authors thank Dr. Eva Heřmanová, University of Economics, Prague, for her advice and valuable comments, and to all 14 directors of regional Public Health Authorities who gave their consent for our questionnaire to be distributed by their employees from the Department of Protection of Public Health and Safety. Special thanks go to the Chief Public Health Officer of Czechia, Vladimír Valenta, M.D., Ph.D. for his personal support of this project and Andrew Mann for linguistic assistance.

\section{REFERENCES}

1. Bobák M, Hertzman C, Škodová Z, Marmot M. Own education, current conditions, parental material circumstances, and risk of myocardial infarction in a former communist country. J Commun Health. 2000;54:91-6, https://doi.org/10.1136/jech. 54.2.91. 
2. Pikhart H. social and psychosocial determinants of self-rated health in Central and Eastern Europe. New York: Springer Science+Business Media; 2002.

3. Kebza V. [Inequalities in health]. Hygiena. 2007;52(1):18-9. Czech.

4. Šplíchalova A, Šlachtová H, Fejtková P, Tomášková H, Polaufová P. [Health indicators and indicators of socioeconomic deprivation in epidemiological studies]. Ostrava: PHI; 2005. Czech.

5. Šplíchalová A, Šlachtová H, Fejtková P, Tomášková H. [Impact of socioeconomic factors on health in epidemiological studies]. Hygiena. 2007;2:51-8. Czech.

6. Jarolímek J, Urban P. Twenty year development of occupational diseases in the Czech Republic: Medical and geographical aspects. Cent Eur J Pub Health. 2014 Dec;22(4):251-6, https://doi.org/10.21101/cejph.a4063.

7. Frazier TM, Sundin DS. Industrial demographics and population at risk for silica exposures. In: Goldsmith DF, Winn DM, Shy CM, editors. Silica, silicosis and cancer. Controversy in occupational medicine. New York: Praeger; 1986.

8. Sundin DS, Frazier TM. Hazard surveillance at NIOSH. Am J Public Health. 1989 Dec;79 Suppl:32-7, https:/doi. org/10.2105/AJPH.79.Suppl.32.

9. Neff RA, Curriero FC, Burke TA. Just in the wrong place...?? Geographic tools for occupational injury/illness surveillance. Am J Ind Med. 2008;51:680-90, https://doi.org/10.10 02/ajim.20611.

10. Foresman TW. The History of geographic information systems. Perspectives from pioneers. New Jersey: Prentice Hall; 1998.

11. Delaunay M, van der Westhuizen H, Godard V, Agius R, le Barbier M, Godderis L, et al. Use of GIS in visualization of work-related health problems. Occup Med. 2015 Nov;65(8):682-92, https://doi.org/10.1093/occmed/kqv152.

12. Vela Acosta MS, Reding DJ, Cooper SP, Gunderson P. Lessons learned: Geographic information systems and farmworkers in the Lake States. J Agric Saf Health. 2005 Feb;11(1):85-97, https://doi.org/10.13031/2013.17899.
13. Falcone U, Gilardi L, Pasqualini O, Santoro S, Coffano E. [Integrated use of data bases to map manufacturing processes involving exposure to carcinogens in the Piedmont Region: The example of formaldehyde]. Med Lav. 2010 MarApr;101(2):83-90. Italian.

14. Crider KG, Maples EH, Gohlke JM. Incorporating occupational risk in heat stress vulnerability mapping. J Environ Health. 2014 Jul-Aug;77(1):16-22.

15. Kamardenn I. E-OHS planning system for builders. Archit Sci Rev. 2011;(54):50-64. https://doi.org/10.3763/asre.2010.0014.

16. Van der Westhuizen H. The representation of hearing conservation data by way of a geographical information system. Occ Health South Africa. 2005;11:28-32.

17. Jarolímek J. [Occupational diseases in the automotive industry in the Central Bohemian region]. Prakt Lek. 2013;93(3):100-4. Czech.

18. Ministry of Industry and Trade. [Panorama of the manufacturing industry in the Czech Republic, 2014]. Prague: The Ministry; 2014. Czech.

19. European Automobile Manufacturers' Association [Internet]. Brussels: The Association; 2015 [cited 2015 Feb 17]. Per capita EU production. Available from: http://www.acea. be/statistics/tag/category/per-capita-production.

20. Pavlínek P, Ženka J. The 2008-2009 automotive industry crisis and regional unemployment in Central Europe. Cambridge J Regions Econ Soc. 2010;3(3):349-65, https://doi. org/10.1093/cjres/rsq026.

21. National Institute of Public Health. [Occupational diseases in Czech 2014]. [Internet]. Prague: The Institute; 2015 [cited 2015 May 3]. Available from: http://www.szu.cz/uploads/ NZP/Hlaseni_odhlaseni_2014.pdf. Czech.

22. Czech Statistical Office [Internet]. Prague: The Office; 2014 [cited 2015 May 3]. [The final census results; 2014]. Available from: https://www.czso.cz/csu/sldb/home. Czech.

23. National Registry of Occupational Diseases [Internet]. Prague: The Registry; 2015 [cited 2015 May 6]. Registry of OD; 2015. Available from: http://www.szu.cz/publicationsand-products/data-and-statistics/occupational. 
24. Pavlínek P, Janák L. Regional restructuring of the Škoda auto supplier network in the Czech Republic. Eur Urban Reg Stud. 2007;14(2):133-55, https://doi.org/ 10.1177/0969776407076101.

25. Pavlínek P, Domański B, Guzik R. Industrial upgrading through foreign direct investment in Central European automotive manufacturing. Eur Urban Reg Stud. 2009;16 (1):43-63, https://doi.org/10.1177/0969776408098932.

26. Public Administration Portal. [The Government services online - the law No. 373/2011 Coll]. [Internet]. Prague: The Portal; 2011 [cited 2015 May 10]. Available from: https:// portal.gov.cz/app/zakony/zakon.jsp?page $=0 \& n r=373 \sim 2 F 2$ 011\&rpp=15\#seznam. Czech.

27. International Labour Organization [Internet]. Geneva: The Organization; 1985 [cited 2015 April 15]. The Convention No. 161/1985. Available from: http://www.ilo.org/dyn/normlex/en/f?p=NORMLEXPUB:12100:0::NO::P12100_ILO_ CODE:C161.

28. statpages.org [Internet] [cited 2015 May 10]. Available from: http://statpages.org.

29. Pavlínek P. The impact of the 2008-2009 crisis on the automotive industry: Global trends and firm-level effects in Central Europe. Eur Urban Reg Stud. 2015;22(1):20-40, https:// doi.org/10.1177/0969776412460534.

30. Eurostat [Internet]. Eurostat; 2016 [cited 2015 May 4]. National accounts aggregates and employment by branch (NACE Rev. 2). National Accounts by 64 branches - Employment data. Manufacture of motor vehicle, trailers and semi-trailers. Available from: http://ec.europa.eu/eurostat/ data/database?node_code $=$ nama_nace64_e.

31. Jedlička J, Kozelský T, Majchráková J. [Analysis of the automotive industry]. [Internet]. Prague: Česká spořitelna; 2013 [cited 2014 Dec 3]. Available from: http://www.csas.cz/static_ internet/cs/Evropska_unie/Specialni_analyzy/Specialni_analyzy/Prilohy/euspa_analysis_of_the_automobile_industry. pdf. Czech.
32. Pelclová D, Fenclová Z, Klusáčková P, Lebedová J, Machovcová $\mathrm{A}$, Petrik V, et al. [Occupational diseases and intoxication]. Prague: Karolinum; 2006. Czech.

33. Ženka J, Pavlínek P. [The Czech automotive industry in global production networks: Regional dimensions of upgrading between 1998 and 2008]. Geografie. 2013;118(2):166-37. Czech

34. Yakut Y, Uçmak D, Akkurt ZM, Akdeniz S, Palanci Y, Sula B. Occupational skin diseases in automotive industry workers. Cutan Ocul Toxicol. 2014 Mar;33(1):11-5, https:// doi.org/10.3109/15569527.2013.787088.

35. McDonald JC, Beck MH, Chen Y, Cherry NM. Incidence by occupation and industry of work-related skin diseases in the United Kingdom, 1996-2001. Occup Med (Lond). 2006 Sep;56(6):398-405.

36. Randolph BW, Lalloo UG, Gouws E, Colvin MS. An evaluation of the respiratory health status of automotive spraypainters exposed to paints containing hexamethylene diisocyanates in the greater Durban area. S Afr Med J. 1997 Mar;87(3):318-23.

37. Nelson NA, Park RM, Silverstein MA, Mirer FE. Cumulative trauma disorders of the hand and wrist in the auto industry. Am J Public Health. 1992 Nov;82(11):1550-2, https:// doi.org/10.2105/AJPH.82.11.1550.

38. Stocks SJ, McNamee R, van der Molen FH, Paris C, Urban P, Campo G, et al. Trends in incidence of occupational asthma, contact dermatitis, noise-induced hearing loss, carpal tunnel syndrome and upper limb musculoskeletal disorders in European countries from 2000 to 2012. Occup Environ Med. 2015 Apr;72(4):294-303, https://doi.org/10.1136/ oemed-2014-102534.

39. EUR-Lex. Access to European Union law. Micro-, smalland medium-sized enterprises: definition and scope [Internet]. Luxembourg: European Union [cited 2015 May 4]. Available from: http://eur-lex.europa.eu/legal-content/EN/ TXT/?uri=LEGISSUM:n26026.

This work is available in Open Access model and licensed under a Creative Commons Attribution-NonCommercial 3.0 Poland License - http://creativecommons.org/ licenses/by-nc/3.0/pl/deed.en. 